\title{
Géza Alföldy \\ (Budapest 1935 - Atenas 2011)
}

FRANCISCO BELTRÁN LLORIS*

El 6 de noviembre pasado fallecía a los 76 años Géza Alföldy, sin lugar a dudas uno de los más influyentes historiadores modernos de la Roma imperial y el investigador «who contributed more to the progress of Latin Epigraphy, and in particular to Corpus Inscriptionum Latinarum, than any other individual scholar since Mommsen», ${ }^{1}$ una apreciación justísima que subraya su enorme talla como epigrafista. El profesor Alföldy deja un inmenso legado científico compuesto por más de quinientos trabajos consagrados a muy diversos aspectos de la historia del Imperio Romano — la sociedad, la administración, el ejército, las provincias, la historiografía y, desde luego, la epigrafía - e incluso a la historia contemporánea de su Hungría natal, caso de Ungarn 1956: Aufstand, Revolution, Freiheitskampf (1997) que demuestra su condición de historiador en todo el sentido del término². Entre ellos se cuentan contribuciones absolutamente fundamentales como, en particular, su Römische Sozialgeschichte $\left(1975,2011_{4}\right)$ —recién traducida al castellano: Nueva historia social de Roma (2012) - , sus monografías sobre los senadores de época antonina, Konsulat und Senatorestand unter den Antoninen (1977), o sobre la crisis del siglo III, Die Krise des römischen Reiches (1989), su clarificador ensayo sobre el concepto de romanización, Romanisation - Grundbegriff oder Fehlgriff? (2005), e, incluso, una reflexión sobre el Imperio Romano como modelo de la Co-

* Facultad de Filosofía y Letras, Universidad de Zaragoza/Grupo de Investigación Hiberus, Pedro Cerbuna, 12, 50.009 Zaragoza: fbeltran@unizar.es

1 En palabras de Stephen Mitchell, presidente de la Association Internationale d'Epigraphie Grecque et Latine (http://www.aiegl.org/nouvelles_de_laAIEGL_it.html).

2 Puede verse una relación de sus publicaciones -citadas aquí de manera abreviada-y de su curriculum académico en la página web de la Universidad de Heidelberg (http://www.uni-heidelberg.de/fakultaeten/philosophie/zaw/sag/alfoeldy.html) así como en la de la Biblioteca Arqueológica Virtual (http://www.ua.es/personal/juan.abascal/alfoldy_geza.html).

3 EDH, http://edh-www.adw.uni-heidelberg.de. 
munidad Europea, Das Imperium Romanum - Ein Vorbild für das vereinte Europa? (1999), que subraya la profunda convicción europeísta de este húngaro emigrado a Alemania en 1965 e íntimamente vinculado a otros países del continente como Italia o España. Seminal es desde luego su aportación al conocimiento de las inscripciones latinas del Principado: desde sus estudios sobre el nacimiento de la cultura epigráfica imperial, «Augustus und die Inschriften: Tradition und Innovation»(Gymnasium 1991) o Studi sull'epigrafia augustea e tiberiana di Roma (Vetera 8, 1992), y acerca de las inscripciones como medio de autorrepresentación, Inschriftliche Denkmäler als Medien der Selbstdarstellung in der römischen Welt (2001, con S. Panciera), pasando por el impulso al Corpus Inscriptionum Latinarum, proyecto del que fue muchos años director (1995-2007) y en el que editó varios fascículos de los volúmenes $\mathrm{VI}$ y $\mathrm{II}^{2}$, hasta la puesta en marcha del pionero Epigraphische Datenbank Heidelberg en 1986, uno de los primeros bancos electrónicos epigráficos ${ }^{3}$. Particular atención prestó, además, a la historia de las provincias occidentales como Panonia, Dalmacia, Germania, la Galia Cisalpina y el norte de Italia, y, especialmente, Hispania.

La aportación de Géza Alföldy al estudio de Hispania y sus inscripciones supone un auténtico turning point en la historiografía reciente. Sus Fasti Hispanienses (1969) —actualizados en 2007- levantaron el andamiaje sobre el que todavía se sostiene hoy el conocimiento de la administración de las provincias peninsulares. Y Die römischen Inschriften von Tarraco (1975), puestas al día en CIL II2/14.2 (2011), aportaron el modelo para la elaboración de un corpus epigráfico moderno en el que varias generaciones de epigrafistas nos hemos inspirado. Las inscripciones del norte de la Comunidad Valenciana, reunidas en CIL II²/14.1 (1995), del acueducto de Segovia (1997, 2010), del arco de Medinaceli (2002), de Segóbriga (2011), y las de diversas procedencias recogidas en su serie de artículos «Epigraphia Hispanica»(ZPE, 1981-1994), entre otras muchas, fueron objeto de ediciones y estudios plenos de acribia, realizados en solitario o en colaboración con otros estudiosos hispanos. Sus monografías sobre los flamines de la Citerior (1973), los Baebii de Sagunto (1977), las ciudades de la Meseta (1987), la cultura epigráfica de Levante $(1995)$ y de Hispania en general $(1998,1999,2011)$, la efímera provincia Hispania Superior $(2000)$, el edicto del Bierzo $(2000,2001)$ o, por no alargar más esta lista forzosamente subjetiva y parcial, su ensayo sobre la Hispania romana, «In omnes provincias exemplum»(2002), constituyen en conjunto la mayor contribución personal al conocimiento de la Hispania romana de los tiempos modernos.

No siempre la labor de un investigador es suficientemente reconocida en vida. El hecho de que no sea este el caso del profesor Alföldy, subraya de manera contundente como, junto con el respeto científico por su obra, Géza supo ganarse el afecto y el agradecimiento de la comunidad científica. Así lo pone de manifiesto la abrumadora nómina de distinciones obtenidas a lo largo de su carrera: caso de premios científicos como los conferidos en Hungría —medalla Kuzsinszky (1965) - Alemania - Leibniz (1986) o Max Planck (1992) - o España -Creu de Sant Jordi (2001) - y, sobre todo, de los diez doctorados honoris causa, de los que tan orgulloso se sentía, otorgados por las universidades Autónoma de Barcelona (1988), Pécs (1992), Budapest (1992), Lyon III (1996), Bolonia (2002), Cluj-Napo- 
ca (2004), Debrecen (2005), Tarragona (2009), Viena (2011) y, en último lugar, Corfú (2011), a dónde se dirigía cuando la muerte, siempre inoportuna, le sorprendió en Atenas. Tras su fallecimiento, que conmocionó profundamente a los medios académicos europeos, se han sucedido los obituarios ${ }^{4}$, homenajes y actos conmemorativos como, por citar sólo tres, los celebrados en su Budapest natal o en Heidelberg, la universidad en la que profesó entre 1975 y 2005, o el que se anuncia para el próximo noviembre en Tarragona, una ciudad a la que se sentía particularmente vinculado y que le sirvió de puerta de entrada a España en 1968, cuando preparaba sus Fasti Hispanienses.

El trabajo epigráfico de Géza Alföldy constituye un modelo magistral por su rigor en la edición, la atención a soportes y contexto arqueológico, la precisión en la datación y el cuidado por los aspectos prosopográficos, insertando el epígrafe siempre en su contexto histórico y tomando en consideración su papel como medio de comunicación social.

Pero Géza no fue sólo un trabajador infatigable, un gran investigador y un hombre comprometido con su tiempo. Fue también un maestro y un amigo. Para quienes como yo nos encontrábamos en pleno período de formación a fines de los años 70 del siglo pasado, supuso no sólo una fuente inagotable de feraz y generoso magisterio, sino que nos abrió además las puertas de Europa, en una época en la que España no contaba ni con las bibliotecas adecuadas ni con una masa crítica de investigadores ni ofrecía tampoco demasiadas posibilidades para salir al extranjero. Heidelberg se convirtió así en meta del peregrinaje de muchos jóvenes investigadores españoles que encontramos en Géza un referente y en esa universidad alemana, fondos bibliográficos excelentes, seminarios especializados de alto nivel, profesores visitantes de gran prestigio y una pléyade de colegas en formación, alemanes y de otros muchos países europeos, con los que anudamos firmes vínculos que en muchos casos prevalecen hasta hoy.

Personalmente, sólo puedo tener palabras de gratitud hacia Géza. Tuve la fortuna -aunque entonces no lo percibiera así- de realizar mi tesis de doctorado sobre un conjunto epigráfico, las inscripciones de Sagunto, en las que él estaba trabajando por ese mismo tiempo. Esta circunstancia que podría haberle impulsado a recibir mi monografía saguntina de 1980 con prevención se tradujo, sin embargo, en una larga reseña, publicada en AEspA de 1981, en la que, sin prescindir de la crítica, realizaba una valoración muy positiva de mi trabajo. Su generosidad le llevó incluso a invitarme a visitar Heidelberg, donde me trató con una deferencia que un joven investigador como yo difícilmente podía esperar, y, algún tiempo después, a participar en la redacción de las fichas para el CIL II2/14, que, sabedor yo de que las schedae estaban prácticamente completas, me limité a aceptar sólo para algunos epígrafes aragoneses. Se cimentó en esos años un respeto y una

4 Entre las diversas notas necrológicas destacaré sólo algunas contribuciones españolas como las de J. M. Abascal (Veleia 28, 2011, 319-328), M. Mayer (SEBarc 9, 2011, 11-16), F. Pina (AEspA 84 $2011,7-8$ ) o la dirigida por I. Rodà (http://icaquencs.icac.net/intranet/moduls/ftp/upload/cbadia/ alfoldy_dossier.pdf). 
amistad, renovados a lo largo de los años en congresos y actos académicos, en intercambios epistolares o en sus múltiples visitas a España. Las charlas apasionadas sobre sus investigaciones, a menudo en torno a una mesa y un buen vino, siempre rebosaban de novedades y sugerencias. A lo largo de los años los escritos de Géza han constituido una fuente inagotable de aprendizaje e inspiración: su artículo de 1991 sobre Augusto y la cultura epigráfica romana, por ejemplo, fue uno de los estímulos que me espoleó a adentrarme en la epigrafía como medio de comunicación social y a organizar el coloquio sobre el nacimiento de la cultura epigráfica en occidente, editado en 1995, en el que Géza participó brillantemente y que valoraba de manera particular. Siempre recordaré con emoción la generosidad y el oficio con los que me presentó cuando en 2002 di a conocer por primera vez los resultados de mi trabajo sobre la Lex riui Hiberiensis en la Escuela Española de Roma. O la ternura con la que buscaba por las tiendas de Barcelona la camiseta de cierto futbolista para un nieto. Dos de nuestros últimos encuentros fueron en su querida Tarragona: el primero, agridulce, todavía convaleciente de la larga enfermedad que le mantuvo postrado entre 2005 y 2008, cuando acudió, acompañado de su esposa Sigrid, para recibir la medalla de Plata de la ciudad en junio de ese último año; y el segundo, ya en plena forma, unos meses antes de morir, cuando presentó exultante en mayo de 2011 el primer volumen del nuevo CIL tarraconense, en el que había trabajado febrilmente en los últimos años.

Seguramente, muchos otros colegas podrán referir experiencias similares, rebosantes de respeto científico y de gratitud. Por eso cuando Átropo, la inexorable, decidió segar el fino hilo de su vida el 6 de noviembre de 2011 nos privó de un maestro y un amigo que deja en nosotros un desolado vacío que sólo los recuerdos personales y su deslumbrante obra científica permiten en parte colmar. Al menos, la parca tuvo la deferencia de elegir para su forzoso mutis un marco adecuado a su talla: la acrópolis de Atenas.

Varias generaciones de estudiosos españoles hemos contraído con él, por su profundo magisterio y su generosa amistad, una deuda de gratitud impagable de la que estas líneas y todo este volumen pretenden dejar emocionada constancia.

Quizá no sea inadecuado para terminar estas líneas invocar las palabras finales de un epitafio tarraconense que Géza editó (RIT 445), en el que los seguidores del auriga Fusco, desolados por su ausencia, le rinden postrero homenaje:

Fundimus insonti lacrimas, nunc uina.

Precamur, ut iaceas placide.

Nemo tui similis.

Zaragoza, 12 de septiembre de 2012 